Supporting information.

\title{
Manipulating the Self-Assembling Process to Obtain Control over the Morphologies of Copper Oxide in Hydrothermal Synthesis and Creating Pores in the Oxide Architecture
} \author{
Ziyi Zhong ${ }^{\mathrm{a}^{*}}$, Vivien $\mathrm{Ng}^{\mathrm{a}}$, Jizhong Luo ${ }^{\mathrm{a}}$, Siew-Pheng Teh ${ }^{\mathrm{a}}$, Jaclyn Teo ${ }^{\mathrm{a}}$, Aharon
Gedanken $^{\mathrm{b}^{*}}$ \\ a Institute of Chemical Engineering and Sciences, 1 Pesek Road, Jurong Island, \\ Singapore 627833 \\ b Department of Chemistry and Kanbar Laboratory for Nanomaterials, \\ Bar-Ilan University Center for Advanced Materials and Nanotechnology, \\ Bar-Ilan University, Ramat-Gan 52900, Israel.
}

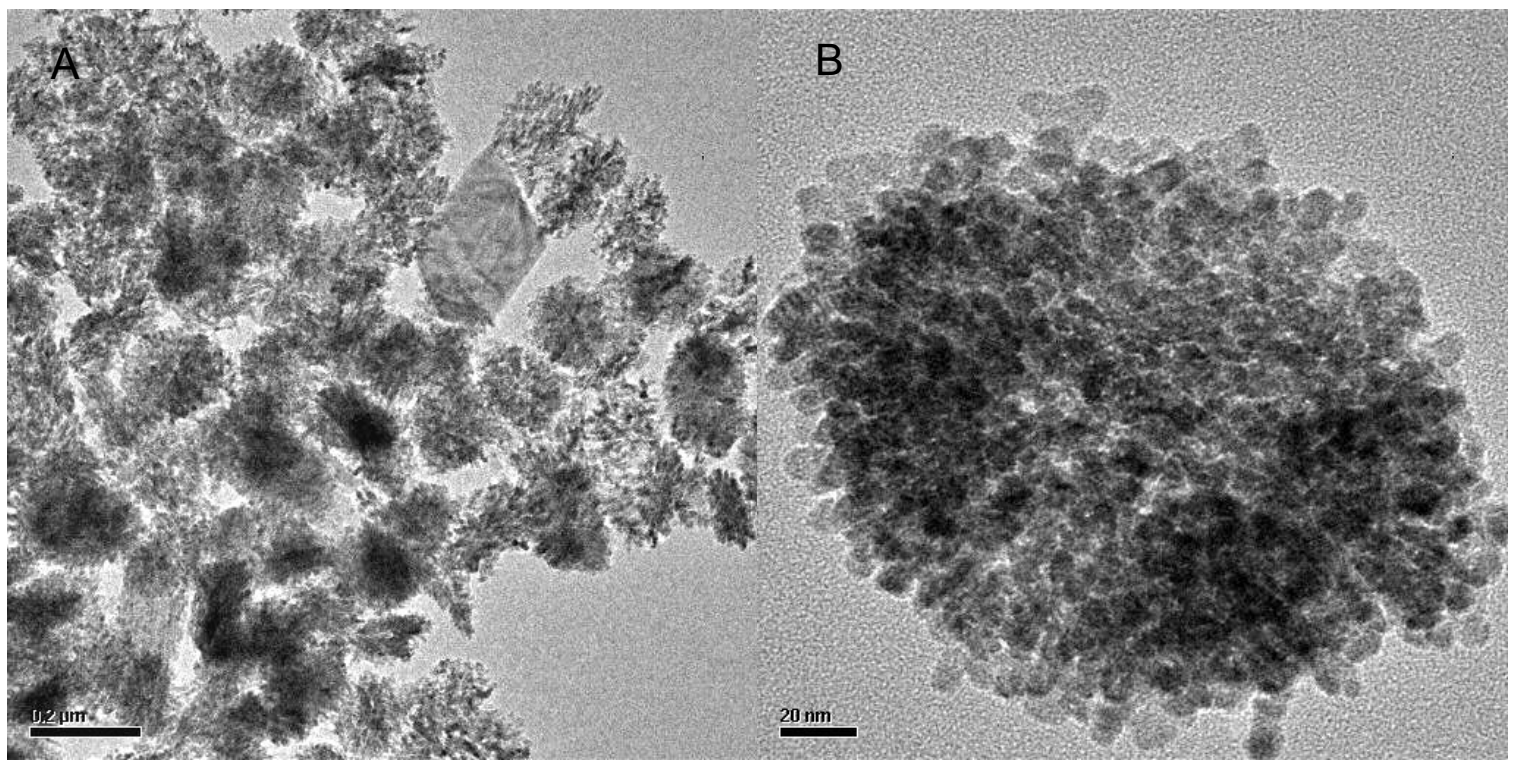

SI-1. Small particles were formed when excess urea was added. In this synthesis, Urea $/ \mathrm{Cu}=15$ and $\mathrm{OLA} / \mathrm{Cu}=2: 1$. Other conditions are: $1.0 \mathrm{~g}$ of $\mathrm{Cu}$ acetate and $10 \mathrm{ml}$ of DI $\mathrm{H}_{2} \mathrm{O}$ were added, and the reaction temperature and time was $80^{\circ} \mathrm{C}$ and $20 \mathrm{~h}$, respectively. 


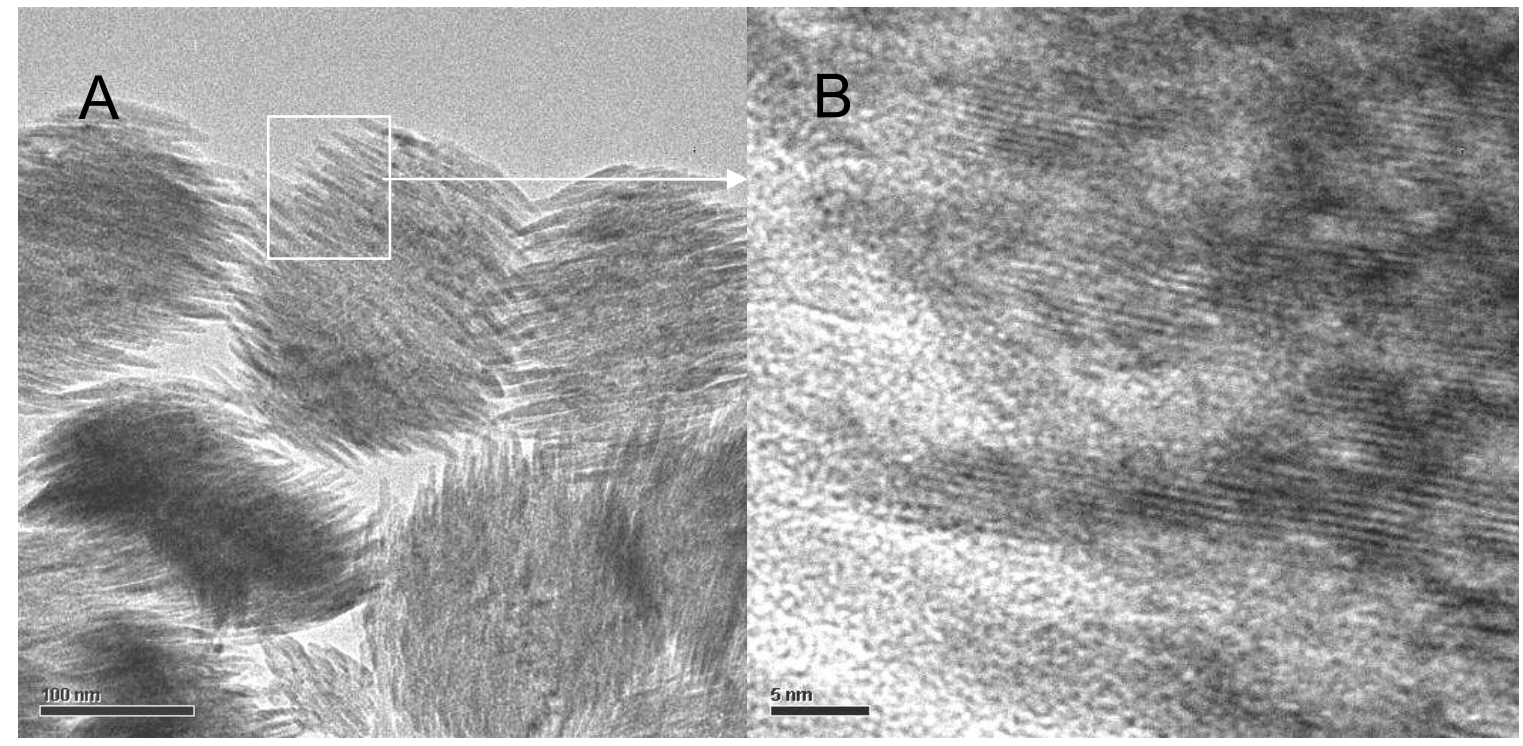

SI-2. TEM images of the spherical Pre-CuO aggregates. The 1D nanostructure is not single crystal but composed of discrete particles. 


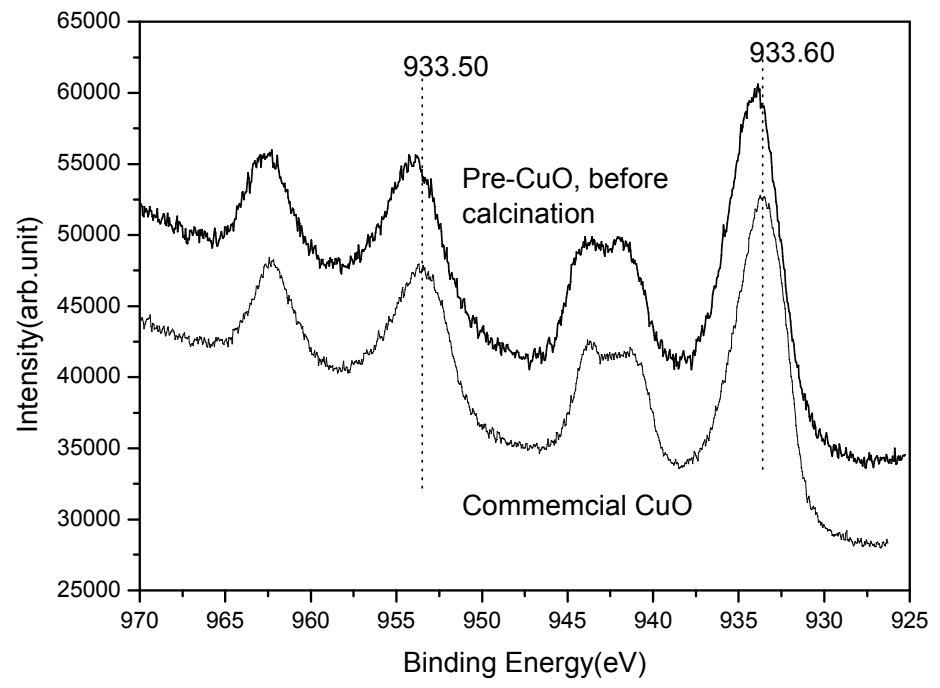

SI-3. XPS spectra of Pro- $\mathrm{CuO}$ and the commercial $\mathrm{CuO}$ purchased from Aldrich.

The binding energy of $\mathrm{Cu} 2 \mathrm{p}$ in $\mathrm{Pre}-\mathrm{CuO}$ is $0.2 \mathrm{eV}$ higher than that of the commercial $\mathrm{CuO}$. Also, the characteristic satellite peaks of $\mathrm{Cu}^{2+}$ are seen. These results indicate that the oxidation state of $\mathrm{Cu}$ in Pre-CuO is still +2 , and no reduction reaction occurred during the hydrolysis reaction of $\mathrm{Cu}(\mathrm{ac})_{2}$. 